\title{
Novel Flux Barrier type Outer Rotor IPM Motor with Rare-earth and Ferrite Magnets
}

\author{
S. Ishii, Y. Hasegawa, K. Nakamura, and O. Ichinokura \\ Graduate School of Engineering, Tohoku University, 6-6-05 Aoba, Aramaki, Aoba-ku, Sendai 980-8579, Japan
}

This paper presents a novel flux barrier type outer rotor interior permanent magnet (IPM) motor that has both rare-earth and ferrite magnets. The proposed IPM motor has two air layers in the outer rotor. The rare-earth magnets are inserted into the first layer, while the ferrite magnets are placed into the second one. The torque of the proposed IPM motor is larger than that of the reference one, although the volume of rare-earth magnets is almost half. Both the magnet and reluctance torques of the proposed IPM motor have been improved. The validity and availability of the proposed IPM motor were proved by experiments and finite element method (FEM).

Keywords: interior permanent magnet (IPM) motor, outer rotor, flux barrier type, rare-earth magnet, ferrite magnet

\section{Introduction}

Environmental problems and energy conservation are becoming huge issues all over the world. Hence, electric vehicles (EVs) and hybrid electric vehicles (HEVs) have attracted a great deal of attention and have been widely popularized. Interior permanent magnet (IPM) motors are generally used in the power trains of HEVs and EVs since they have a high power-to-weight ratio and are much more efficient than other motors. However, the rare-earth magnets used in IPM motors are expensive, and their supply is unstable since the number of countries that produce them is limited. Therefore, reducing the volume of rare-earth magnets is a very important issue that needs to be resolved.

The above situation has recently led to ferrite magnets being reconsidered as a substitute for rare-earth magnets. Although the residual flux density of ferrite magnets is one-third that of rare-earth magnets, their cost is about one-tenth. In addition, the supply is expected to be stable1).

Several IPM motors with ferrite magnets have been presented ${ }^{2)-4}$. They have a flux barrier type inner rotor structure to increase reluctance torque instead of reduced magnet torque. However, they do pose some problems. First, they require a center rib in the flux barrier to improve mechanical strength in high speed operation. As a result, the flux from the permanent magnet is shorted by the center rib and the effective flux decreases. Second, the inner rotor structure has limited space for inserting ferrite magnets. Third, irreversible demagnetization occurs easily since ferrite magnets have low coercive force.

This paper presents a novel flux-barrier-type outer rotor IPM motor with rare-earth and ferrite magnets as a potential solution to these problems. The proposed IPM motor requires no center rib because an outer rotor structure is employed. Hence, the shorted flux is decreased, and the effective flux is increased.
Furthermore, the outer rotor structure has a large space for inserting ferrite magnets. The proposed IPM motor has a two-air-layered rotor. A small amount of rare-earth magnet is inserted into the first layer since the armature reaction field, which causes irreversible demagnetization, is strong. However, a large amount of ferrite magnet is placed into the second layer where the armature reaction field is weak.

In this paper, first, characteristics of the proposed IPM motor are calculated by finite element method (FEM), and compared to those of a reference IPM motor. Next, experimental results are described to prove the validity and availability of the proposed IPM motor.

\section{Characteristics of proposed IPM motor}

\subsection{Specifications of proposed IPM motor}

Fig. 1(a) shows the shape and dimensions of the reference outer rotor IPM motor, which has 16 poles and 24 slots with concentrated windings. The parallel magnetized $\mathrm{Nd}-\mathrm{Fe}-\mathrm{B}$ magnets are buried to form a $\mathrm{V}$-shape as shown in the figure. The core material is non-oriented Si steel with a thickness of $0.35 \mathrm{~mm}$.

Fig. 1(b) illustrates the proposed IPM motor, which has the same stator core and windings as the reference motor. The rotor, on the other hand, has a two-air layered structure.

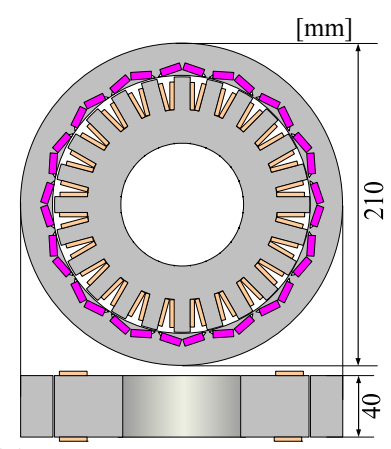

(a) Reference IPM motor

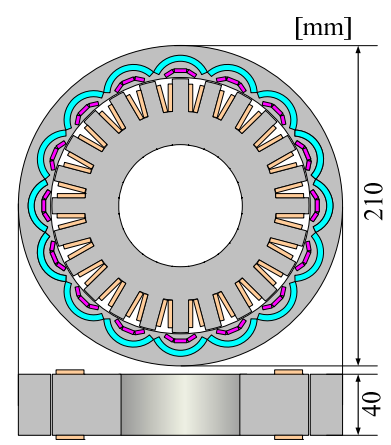

(b) Proposed IPM motor
Fig. 1 Shapes and dimensions of IPM motors. 
Table 1 Specifications of IPM motors.

\begin{tabular}{|c|c|c|}
\hline & $\begin{array}{c}\text { Reference } \\
\text { IPM motor }\end{array}$ & $\begin{array}{c}\text { Proposed } \\
\text { IPM motor }\end{array}$ \\
\hline Number of slots (Stator) & \multicolumn{2}{|c|}{24} \\
\hline Number of poles (Magnet) & \multicolumn{2}{|c|}{16} \\
\hline Number of winding turns & \multicolumn{2}{|c|}{32} \\
\hline Winding resistance/phase & \multicolumn{2}{|c|}{$36 \mathrm{~m} \Omega$} \\
\hline Core material & Non-oriented Si steel \\
\hline Permanent magnet & Nd-Fe-B & $\begin{array}{c}\text { Nd-Fe-B } \\
\text { Ferrite }\end{array}$ \\
\hline
\end{tabular}

Table 2 Specifications of permanent magnets

\begin{tabular}{|c|c|c|}
\hline & $\begin{array}{c}\text { Rare-earth } \\
\text { magnet }\end{array}$ & $\begin{array}{c}\text { Ferrite } \\
\text { magnet }\end{array}$ \\
\hline Coercive force $H_{c}(\mathrm{kA} / \mathrm{m})$ & 962 & 325 \\
\hline Residual flux density $B_{r}(\mathrm{~T})$ & 1.25 & 0.44 \\
\hline Recoil permeability & 1.03 & 1.08 \\
\hline
\end{tabular}

The volume of the rare-earth magnet, which is inserted into the inside layer, is half that of the reference motor, while an arc-shaped ferrite magnet, which is radial magnetized, is located in the outside layer in the rotor. Tables 1 and 2 indicate the specifications for both the IPM motors and magnets.

\subsection{Characteristics of proposed IPM motor}

Characteristics of the proposed IPM motor are compared to those of the reference IPM motor by using two-dimensional FEM (2D-FEM). Fig. 2(a) outlines a 2D-FEM model of the proposed IPM motor. Fig. 2(b) shows a motor-driving circuit model, which is coupled with the FEM model.

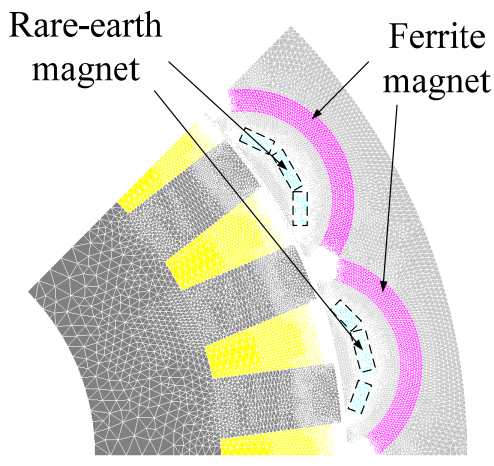

(a) Two-dimensional FEM model

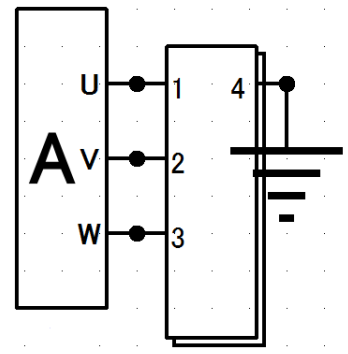

(b) Motor driving circuit model

Fig. 2 Analytical model of proposed IPM motor.
Fig. 3 plots the current density versus torque characteristics at $1000 \mathrm{rpm}$. The IPM motor is excited by the ideal three-phase sinusoidal current with a phase angle of $35^{\circ}$. It reveals that the torque of the proposed IPM motor is larger than that of the reference one. Figure 4 indicates the proportion of magnet and reluctance torques for both the IPM motors when the current density is $20 \mathrm{~A} / \mathrm{mm}^{2}$. It is understood from the figure that both the magnet and reluctance torques of the proposed IPM motor are improved. Figure 5 plots the torque versus phase angle characteristics. It is clear that the torque improvement of the proposed IPM motor is greatly dependent on the magnet torque.

Table 3 compares the magnet volume and the maximum torque of the reference and proposed IPM motors. The volume of rare-earth magnet in the proposed IPM motor is about half that of the reference one. However, the torque of the proposed IPM motor is 1.21 times larger. Although the proposed IPM motor requires ferrite magnets, their total cost will be reduced since they are fairly inexpensive.

In order to clarify the reason why both the magnet and reluctance torques were improved, the flux linkage under no-load conditions and $d$-axis and $q$-axis inductances are investigated because the torque of the IPM motor is given by

$$
T=p\left\{\phi_{a} i_{q}+\left(L_{q}-L_{d}\right) i_{d} i_{q}\right\}
$$

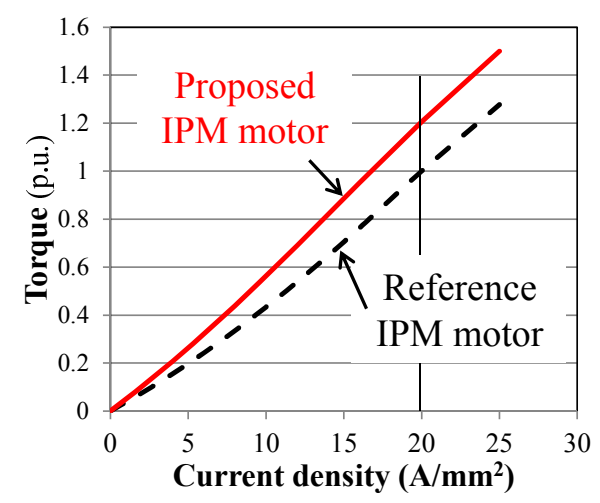

Fig. 3 Current density versus torque characteristics of reference and proposed IPM motors.

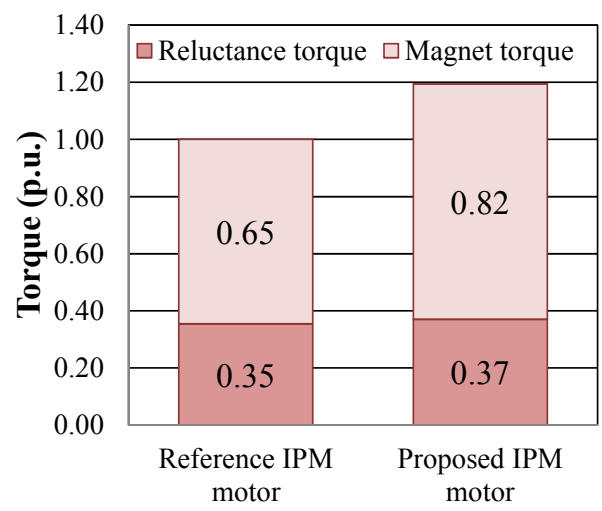

Fig. 4 Proportion of magnet and reluctance torques of both IPM motors at current density of $20 \mathrm{~A} / \mathrm{mm}^{2}$. 


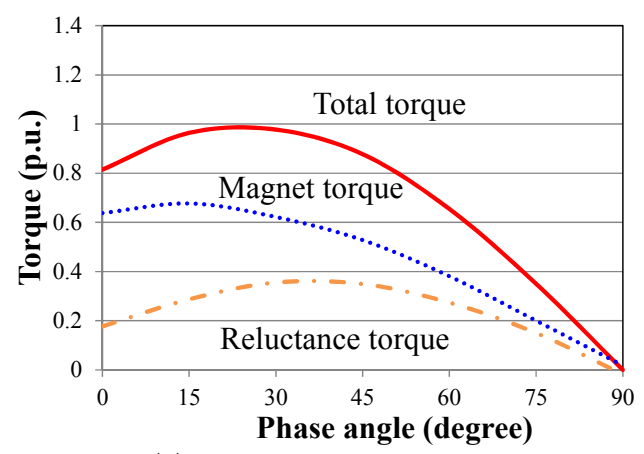

(a) Reference IPM motor

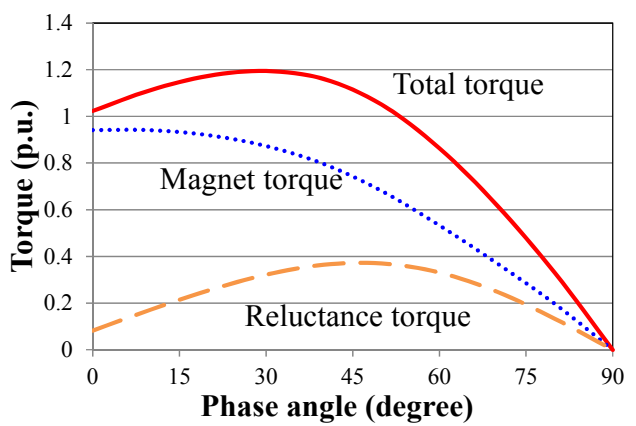

(b) Proposed IPM motor

Fig. 5 Torque versus phase angle characteristics

Table 3 Comparison of magnet volume and maximum torque of both IPM motors.

\begin{tabular}{|c|c|c|c|}
\hline \multicolumn{2}{|c|}{} & $\begin{array}{c}\text { Reference } \\
\text { IPM motor }\end{array}$ & $\begin{array}{c}\text { Proposed } \\
\text { IPM motor }\end{array}$ \\
\hline \multirow{2}{*}{\begin{tabular}{c} 
Magnet $\begin{array}{c}\text { volume } \\
\text { (p.u.) }\end{array}$ \\
\cline { 2 - 4 }
\end{tabular}} & Rare-earth & 1.0 & 0.56 \\
\hline \multicolumn{2}{|c|}{$\begin{array}{c}\text { Maximum torque } \\
\text { at } 20 \mathrm{~A} / \mathrm{mm}^{2} \text { (p.u.) }\end{array}$} & 0.0 & 1.82 \\
\hline
\end{tabular}

where the number of pole-pairs is $p$, the effective magnet flux is $\phi_{a}$, the $d$-axis and $q$-axis inductances are $L_{d}$ and $L_{q}$, and the $d$-axis and $q$-axis currents are $i_{d}$ and $i_{q}$.

Figure 6 shows the calculated waveforms of flux linkage under no-load conditions, i.e., the figures indicate the effective magnet flux. It is clear that the amplitude of flux linkage in the proposed IPM motor is larger than that of the reference one. Therefore, the magnet torque is increasing.

Table 4 lists the calculated $d$-axis and $q$-axis inductances at a current density of $20 \mathrm{~A} / \mathrm{mm}^{2}$. It is clear that the ratio of salient pole $L_{q} / L_{d}$ of the proposed IPM motor is slightly larger. Therefore, the reluctance torque is slightly increased.

\subsection{Demagnetization analysis of ferrite magnets}

It is essential to analyze demagnetization in ferrite magnets since coercive force, which is about one third that of $\mathrm{Nd}-\mathrm{Fe}-\mathrm{B}$ magnets, is very low.

An example of a demagnetization curve of a permanent magnet is shown in Fig. 7, where if the working point is above the knee point as point a, then the residual flux density is kept at $B_{r}$. However, if the working point is below the knee point as point $b$ due to the armature reaction field, then the magnet is irreversibly demagnetized, and the residual flux density decreases to $B_{r}$ '.

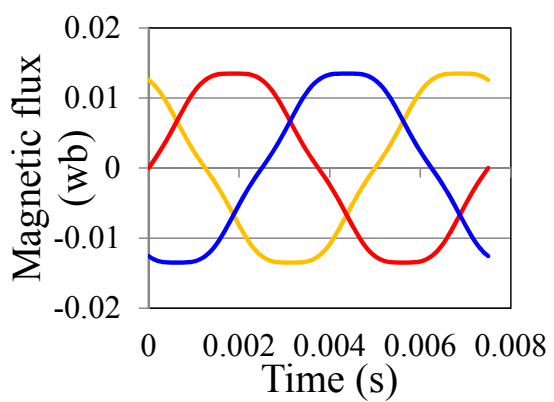

(a) Reference IPM motor

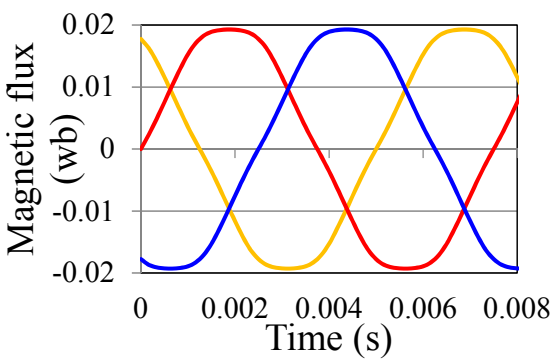

(b) Proposed IPM motor

Fig. 6 Calculated waveforms of flux linkage under no-load conditions.

Table 4 Calculated $d$-axis and $q$-axis inductances of reference and proposed IPM motors

\begin{tabular}{|l|c|c|}
\hline & $\begin{array}{c}\text { Reference IPM } \\
\text { motor }\end{array}$ & $\begin{array}{c}\text { Proposed IPM } \\
\text { motor }\end{array}$ \\
\hline$L_{d}$ & $0.34 \mathrm{mH}$ & $0.33 \mathrm{mH}$ \\
\hline$L_{q}$ & $0.59 \mathrm{mH}$ & $0.60 \mathrm{mH}$ \\
\hline$L_{q} / L_{d}$ & 1.7 & 1.8 \\
\hline
\end{tabular}

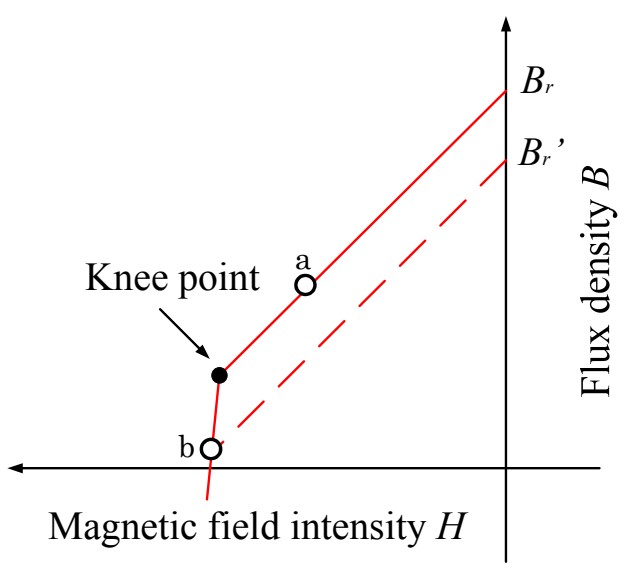

Fig. 7 Schematic of demagnetization curve of permanent magnet. 
The demagnetizing factor is defined in this paper as:

$$
\gamma_{\text {dem }}=\frac{B_{r}-B_{r}^{\prime}}{B_{r}} \times 100(\%) .
$$

A demagnetization curve for the ferrite magnet at a temperature of $-40^{\circ} \mathrm{C}$ was used in the demagnetization analysis because the coercive force of the ferrite magnet is decreased when the temperature is decreasing, i.e., a temperature of $-40^{\circ} \mathrm{C}$ is the most stringent condition. Furthermore, the current density is $40 \mathrm{~A} / \mathrm{mm}^{2}$, which is twice the maximum current density, and the phase angle of the current is $35^{\circ}$ in order to take into consideration a field-weakening control, in which the armature reaction field becomes stronger.

Figure 8 shows a contour diagram of the demagnetizing factors. It is clear that the ferrite magnet in the proposed IPM motor is hardly demagnetized even under the most stringent conditions previously described.

Furthermore, the demagnetization of rare-earth magnets under high-temperature conditions was also investigated. The temperature of the surrounding space was assumed to be $100^{\circ} \mathrm{C}$. The current density was 40 $\mathrm{A} / \mathrm{mm}^{2}$ and the phase angle was $35^{\circ}$. Figure 9 shows a contour diagram of demagnetizing factors, where only a corner of the rare-earth magnet has been demagnetized.

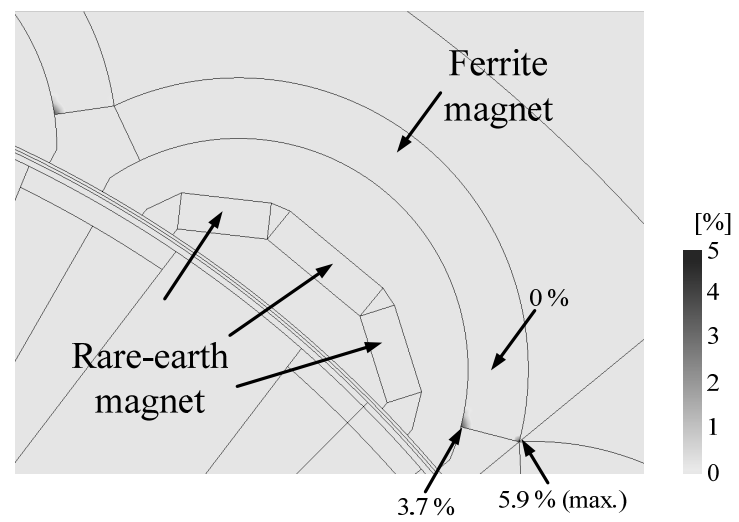

Fig. 8 Contour diagram of demagnetizing factors at low temperature.

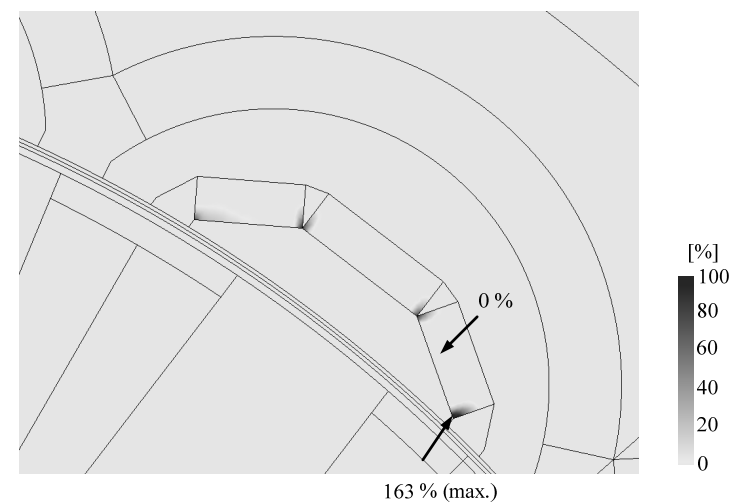

Fig. 9 Contour diagram of demagnetizing factor at high temperature.

\section{Experimental results}

A trial machine was manufactured to prove the validity and availability of the proposed IPM motor. The experimental results are compared to the calculated ones obtained from FEM.

\subsection{Experimental setup and conditions}

Figures 10 and 11 show a photograph of the experimental setup and a block diagram of the experimental system, respectively. The experimental system consists mainly of a digital signal processor (DSP), three-phase full-bridge inverter, trial IPM motor, DC power source, and a dynamometer.

Figure 12 shows the 2D-FEM model. The trial IPM motor is driven by the three-phase full-bridge inverter with a conventional $120^{\circ}$ commutation control.

\subsection{Experimental results}

Figures 13 and 14 show the observed and calculated waveforms of voltage and current, respectively. These figures clearly indicate that the observed and calculated waveforms are mostly in good agreement.

Figure 15 plots the current density versus torque characteristics when the rotational speed is kept constant at $1000 \mathrm{rpm}$ by adjusting the voltage of the DC power source. It is understood that the calculated values agree well with the measured ones, and that the measured torque of the proposed IPM motor is about 1.2 times larger than the calculated torque of the reference one at $9 \mathrm{~A} / \mathrm{mm}^{2}$.

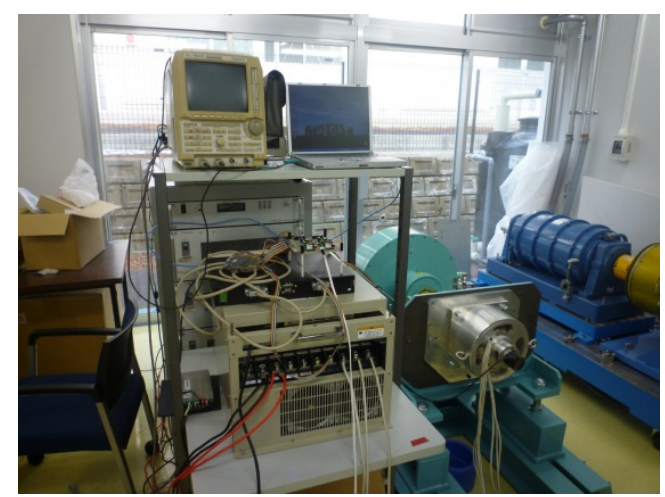

Fig. 10 Experimental setup.

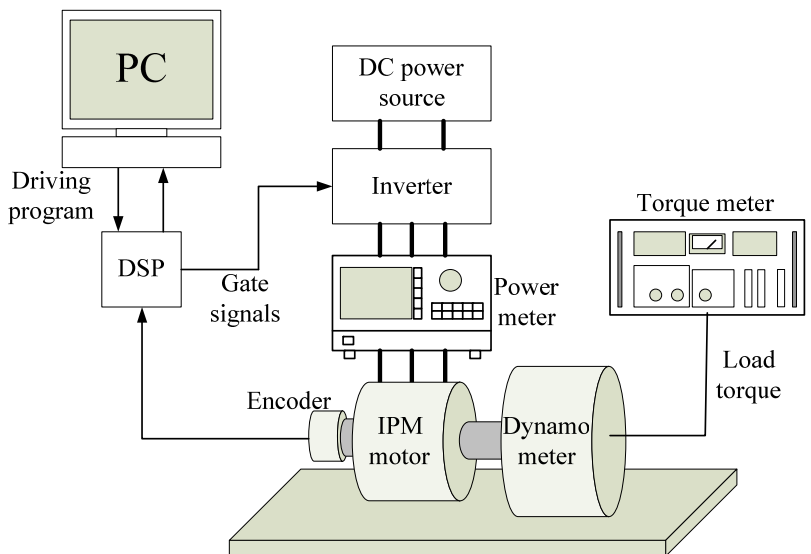

Fig. 11 Block diagram of experimental system. 


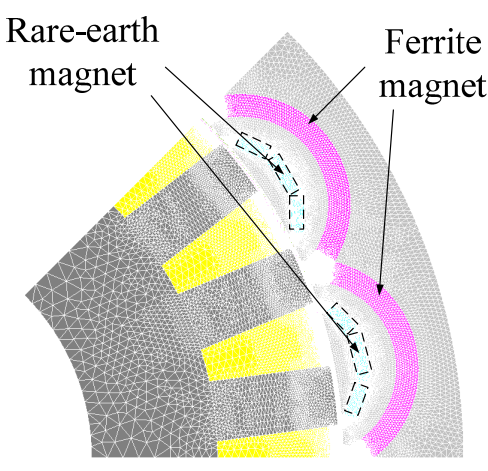

(a) Two-dimensional FEM model

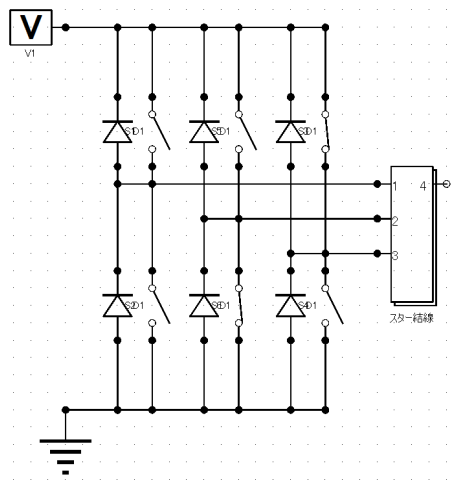

(b) Motor driving circuit model

Fig. 12 Analytical model of proposed IPM motor.

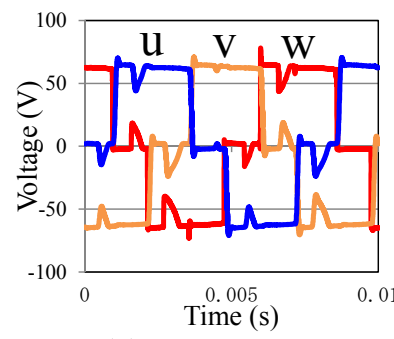

(a) Observed

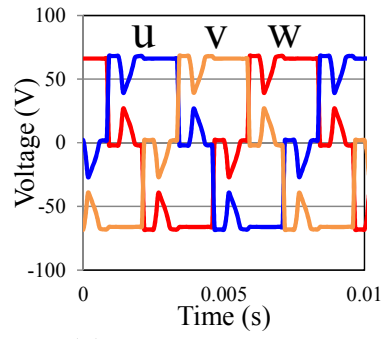

(b) Calculated
Fig. 13 Observed and calculated voltage waveforms.

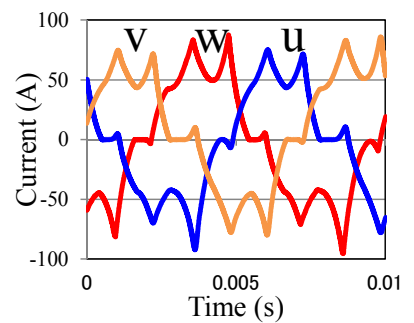

(a) Observed

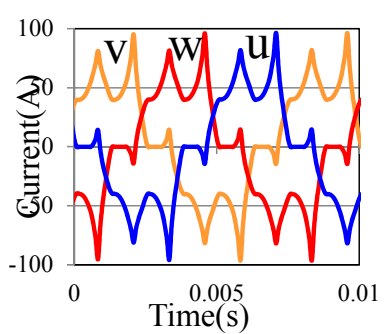

(b) Calculated
Fig. 14 Observed and calculated current waveforms.

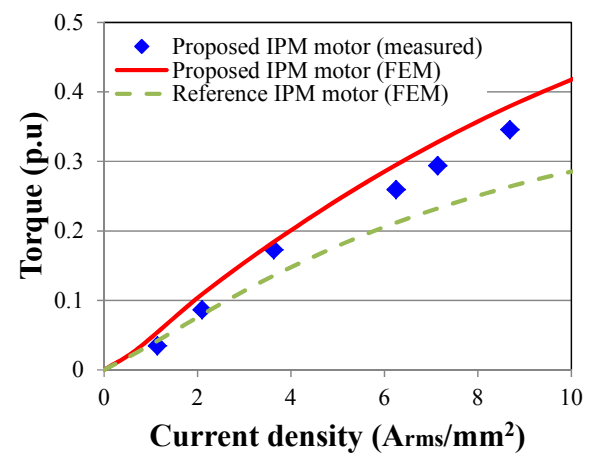

Fig. 15 Current density versus torque characteristics.

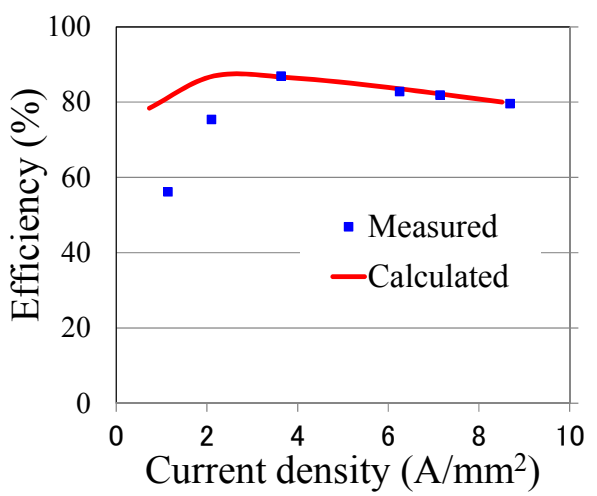

Fig. 16 Current density versus efficiency characteristics.

Figure 16 plots the efficiency of the proposed IPM motor. The efficiency of the proposed IPM motor is given by

$$
\eta=\left(\omega T / P_{\text {in }}\right) \times 100(\%),
$$

where the mechanical angular velocity is $\omega(\mathrm{rad} / \mathrm{s})$, torque is $T(\mathrm{~N} \cdot \mathrm{m})$, and electrical input power $P_{i n}(\mathrm{~W})$. It is clear that the calculated values are in good agreement with the measured ones in the large current density region. However, there is a large quantitative difference between the measured and calculated values in the small current density region because mechanical losses are not considered in FEM.

\section{Conclusion}

This paper presented a novel flux barrier type outer rotor IPM motor that has both rare-earth and ferrite magnets.

It was clear that the torque of the proposed IPM motor was about 1.2 times larger than that of the reference one, although the amount of rare-earth magnet in the proposed IPM motor was about half that in the reference one. Both the magnet and reluctance torques of the proposed IPM motor were improved. Furthermore, it was indicated that the ferrite magnets used in the proposed motor were hardly demagnetized even under severe conditions where the current density was twice the maximum value and the temperature was $-40^{\circ} \mathrm{C}$. The validity and availability of the proposed IPM motor was proved by comparing the experimental results with those from FEM.

A part of this work was supported by JSPS Kakenhi Grant Number 24656180.

\section{References}

1) T. Sun, S. Kwon, J. Lee, J. Hong, INTELEC 2009, pp. 1-6 (2009).

2) S. Ooi, S. Morimoto, M. Sanada, and Y. Inoue, Proc. of IEEE ECCE 2011, pp. 4195-4200 (2011).

3) L. Fang, J. Jung, J. Hong, J. Lee, IEEE Trans. Magn., 44, 4393 (2008).

4) E. Armand, P. Guglielmi, G. Pellegrino, M. Pastorelli, A. Vagati, 42 $2^{\text {nd }}$ IEEE-IAS annual meeting, pp. 133-140 (2007).

Received Oct. 19, 2012; Revised Dec. 20, 2012; Accepted Jan. 8, 2013 